\title{
Rasmussen Syndrome and Other Inflammatory Epilepsies
}

\author{
Sophia Varadkar, MRCPI, $\mathrm{PhD}^{1}$ J. Helen Cross, FRCPCH, $\mathrm{PhD}^{2}$ \\ ${ }^{1}$ Epilepsy Unit, Great Ormond Street Hospital for Children NHS \\ Foundation Trust and UCL Institute of Child Health, London, \\ United Kingdom \\ 2 Department of Clinical Neurosciences, UCL-Institute of Child Health,

\begin{abstract}
Address for correspondence J. Helen Cross, FRCPCH, PhD, Department of Clinical Neurosciences, UCL-Institute of Child Health, Great Ormond Street for Children NHS Foundation Trust, London and Young Epilepsy, Lingfield, United Kingdom (e-mail: h.cross@ucl.ac.uk).
\end{abstract} Great Ormond Street for Children NHS Foundation Trust, London and Young Epilepsy, Lingfield, United Kingdom

Semin Neurol 2015;35:259-268.

\begin{abstract}
Keywords

- Rasmussen syndrome

- Rasmussen encephalitis

- epilepsy

- immune

- antibody

- encephalitis

- N-methyl-D-aspartate receptor

- voltage-gated potassium channel

- febrile infectionrelated epilepsy syndrome

An underlying immune basis is emerging in an increasing number of epileptic and encephalopathic syndromes. The immunopathological mechanisms may be categorized into antibody-mediated, T-cell cytotoxicity, and microglia-induced degeneration. The immune basis in Rasmussen syndrome is thought to be T-cell mediated. Antibodies to extracellular and intracellular epitopes are implicated in limbic and other encephalitides, characterized by seizures, movement disorder, sleep disorder, obtundation, psychosis, mutism, and other psychiatric symptoms. Extracellular antibodies are directed at cell-surface-expressed neuronal or glial proteins: glutamate receptors ( $\mathrm{N}$ methyl-D-aspartate and $\alpha$-amino-3-hydroxy-5-methyl-4-isoxazol-propionic acid), voltage-gated potassium channel complex (contactin-associated-protein 2 [CASPR2], contactin-2 and leucin-rich, glioma-inactivated 1 [LGI1]), and $\gamma$-aminobutyric acid (GABA) receptors $\left(G A B A_{B} R\right.$ and $\left.G A B A_{A} R\right)$. Antibodies to intracellular antigens are less commonly seen (for example, glutamic acid decarboxylase). Diseases caused by antibodies to cellsurface-expressed antigens are better expected to respond to immune treatments than to those where the presumed mechanism is T-cell driven. Antibodies to the folate receptor FR1 are a cause of primary cerebral folate deficiency. Febrile infection-related epilepsy syndrome (FIRES) may also have an immune basis, although this is yet to be proven. For all these epilepsies, the best treatment and the long-term outcomes are not yet clear.
\end{abstract}

An immune basis is thought to be underlying an increasing number of epileptic and encephalopathic syndromes. This is of increasing importance, particularly in the optimization of management, considering a mechanistic basis to steroids and immunosuppressive therapy. Although traditionally the brain has been thought to be protected against the humoral immune system, the descriptions in the past 10 years of several different central nervous system (CNS) conditions associated with potentially pathogenic circulating antibodies to neuronal surface proteins demonstrate that this is not the case. Rasmussen syndrome (RS) is one such inflammatory epilepsy, long presumed to have an immune basis. ${ }^{1}$ It was in this condition that an autoantibody was identified, against GluR3 (now termed GluA3), and not surprisingly antibody-mediated mechanisms subsequently dominated RS research. ${ }^{2}$ Although it has become clear that antibodies are unlikely to drive RS, it is still thought to have an autoimmune basis (T-cell mediated). There are now other epilepsies in which the evidence strongly implicates autoantibodies as pathogenic and that respond to immunotherapies. ${ }^{3,4}$ In general, these antibodies have extracellular targets, and seem to alter the function and localization of these target antigens. The diseases have various symptoms including seizures, movement disorder, sleep disorder, psychosis, mutism, limbic encephalitis, and
Issue Theme Etiology of Epilepsy; Guest Editors: Philip Smith, MD, FRCP,

FAcadMEd, and Rhys Thomas, BSc, MRCP, MSc, PhD
Copyright $\odot 2015$ by Thieme Medical Publishers, Inc., 333 Seventh Avenue, New York, NY 10001, USA. Tel: +1(212) 584-4662.
DOI http://dx.doi.org/ 10.1055/s-0035-1552921. ISSN 0271-8235. 
encephalopathy. The diagnosis is suspected on the clinical picture and confirmed with the detection of the antibodies in serum or in cerebrospinal fluid (CSF). The most important of these antibodies to date are those targeted against glutamate receptors and against the voltage-gated potassium channel (VGKC complex). The immunopathological mechanisms recognized to play a role in CNS disease can now be categorized into three types: antibody-mediated, T-cell cytotoxicity, and microglia-induced degeneration.

\section{Mechanisms}

Glutamate is the major excitatory amino acid in the CNS. Antibodies to the glutamate N-methyl-D-aspartate (NMDA) receptor are likely pathogenic in what is now termed NMDAR encephalitis. ${ }^{5}$ Antibodies to the VGKC complex were described in the spectrum of limbic encephalitis. ${ }^{6}$ It is now known that there several different antibodies involved in VGKC encephalitis, each targeting different extracellular domains of proteins complexed to the VGKC. Further target epitopes have been reported in the limbic encephalitides: $\alpha$-amino-3-hydroxy-5-methyl-4-isoxazolpropionic acid (AMPA) receptor, ${ }^{7} \gamma$-aminobutyric acid (GABA) receptors, first $\mathrm{GABA}_{B} \mathrm{R}^{8}{ }^{8}$ and most recently GA$\mathrm{BA}_{A} \mathrm{R}^{9}{ }^{9,10}$ These antibodies all have in common target cellsurface-expressed neuronal or glial proteins. ${ }^{3}$

Autoantibodies to intracellular antigens, such as to glutamic acid decarboxylase (GAD) have also been described in antibody-mediated encephalitis and in temporal lobe epilepsy. ${ }^{11}$ In contrast to the diseases characterized by antibodies to extracellular antigens, these diseases do not respond so well to immune treatments and it has been proposed that the pathogenic mechanism here is T-cell driven.

Before recent interest in surface versus intracellular antigens, the autoimmune encephalitides were often categorized according to whether there was a paraneoplastic basis, and whether the onconeural antigens continue to be interest. In adults, a paraneoplastic basis, often related to the presence of lung, thymoma, and gynecological tumors, is important in terms of diagnosis, as treatment of either the underlying malignancy or with immune therapies could lead to speedy resolution of the neurologic disease. Onconeural antigens have not been a significant factor in pediatric disease. Therefore, they are not discussed in detail here.

The electroclinical symptom complex now usually termed FIRES (febrile infection-related epilepsy syndrome) behaves as if it may have an immune basis. Classically, previously normal children present with increasing encephalopathy and seizures, often status epilepticus, after a history of a febrile illness. The illness can be quite devastating. However, although immunosuppressive therapy may be adopted, to which some response can be seen, only a small number have been determined to have positive antibodies.

For all these epilepsies, the best treatment and the longterm outcomes are not yet clear. Here we describe the main clinical syndromes associated with these epilepsies likely of immune origin (-Table 1). We do not discuss in detail the underlying immune bases or address in detail the arguments for or against cellular or humoral immune drivers. Epilepsies or seizures arising secondary to known or presumed acute or infectious causes are not discussed here.

\section{Clinical Syndromes}

\section{Rasmussen Syndrome}

\section{Clinical Syndrome}

Rasmussen syndrome is a rare chronic progressive neurologic disease, characterized by unilateral inflammation and atrophy of the cerebral cortex, drug-resistant focal epilepsy, progressive hemiplegia, and cognitive deterioration. A European consensus panel proposed formal diagnostic criteria for Rasmussen encephalitis (RE) in 2005 that remain valid. ${ }^{12}$ Rasmussen syndrome is mostly a disease of children, though adolescent and older adult cases probably comprise approximately $10 \%$. No gender, geographic, or ethnic predominance has been noted. Recent studies have estimated an incidence of $2 \cdot 4$ cases $/ 10^{7}$ people per year aged $\leq 18$ years in Germany and $1 \cdot 7 / 10^{7}$ people per year aged $\leq 16$ years in the United Kingdom. ${ }^{13,14}$

The typical untreated clinical course is of a median onset at 6 years of age. Though a prodromal stage of mild hemiparesis or infrequent seizures may precede the onset of the acute stage by up to several years, typically the acute stage is characterized by very frequent unilateral seizures, which are drug resistant. In about half of patients, epilepsia partialis continua (EPC) is observed. As the disease progresses, different focal seizure semiologies emerge reflecting newly affected areas of inflammation in the hemisphere. ${ }^{15}$ The disease progresses inexorably to hemiparesis, hemianopia, and cognitive decline, often within a year of epilepsy onset. If the language-dominant hemisphere is affected, speech will be affected. The child or young person is left with severe fixed neurologic deficits, motor and cognitive, and ongoing usually drug-resistant epilepsy. This final relatively stable "residual stage" is deceptively still often termed as "burnout."

As well as adolescent and adult presentations, other atypical presentations are described including unilateral movement disorders, hemiathetosis and hemidystonia, and less clearly RS without seizures. ${ }^{15,16}$ Bilateral disease as confirmed by neuropathology is debated; if it exists, it is very rare.

Magnetic resonance imaging (MRI) of the brain has an essential role in diagnosis and in follow-up. ${ }^{17}$ The greatest change is seen early in the disease process, usually the first 8 months, concordant with the acute clinical phase, and thereafter more gradual progressive unilateral signal change and atrophy (-Fig. 1). Immune-modulating therapies may be attenuating MRI changes. Likewise, the electroencephalogram (EEG) may reflect clinical progression. Initially, as in any of the epilepsies, the EEG may be normal followed within months of seizure onset by the emergence of persistent highamplitude delta activity over the affected hemisphere. Epileptiform abnormalities become frequent and electrographic seizures are not uncommon. Independent interictal abnormalities over the nonaffected hemisphere emerge within 6 months in $25 \%$ and in $62 \%$ of patients within 3 to 5 years 


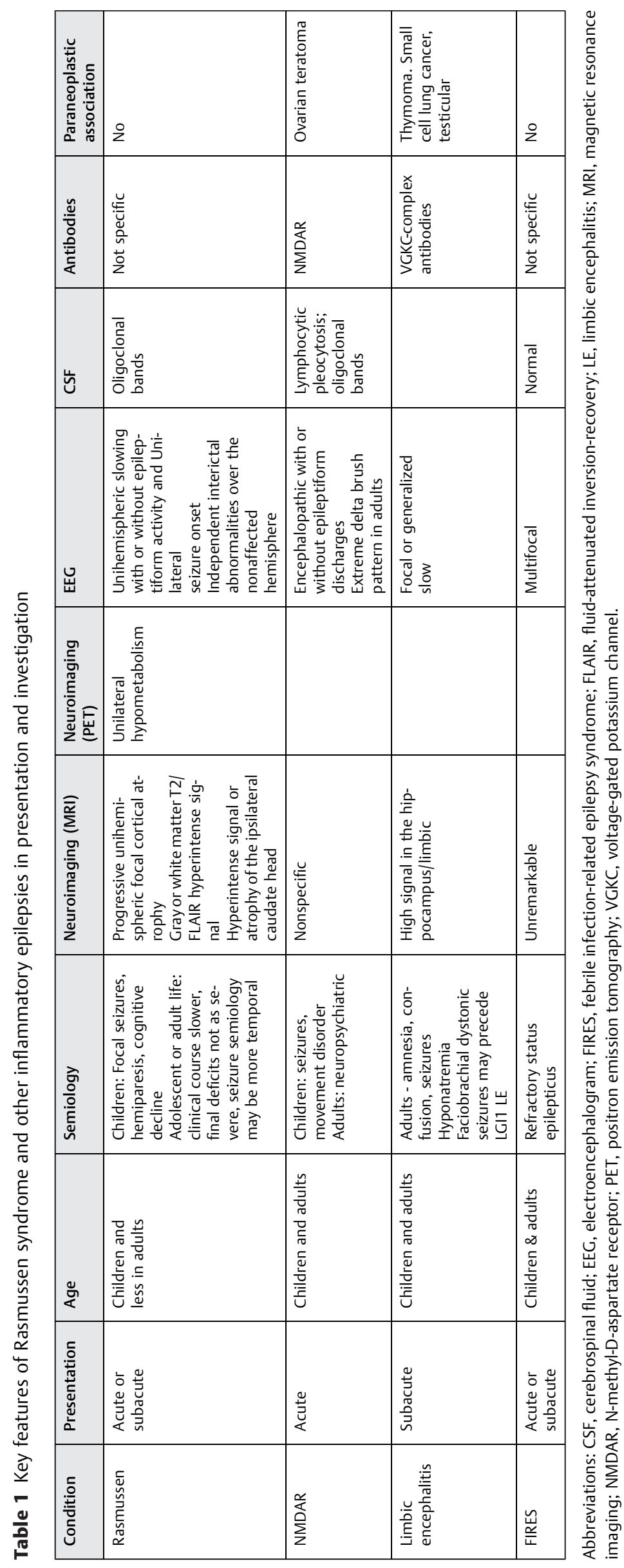



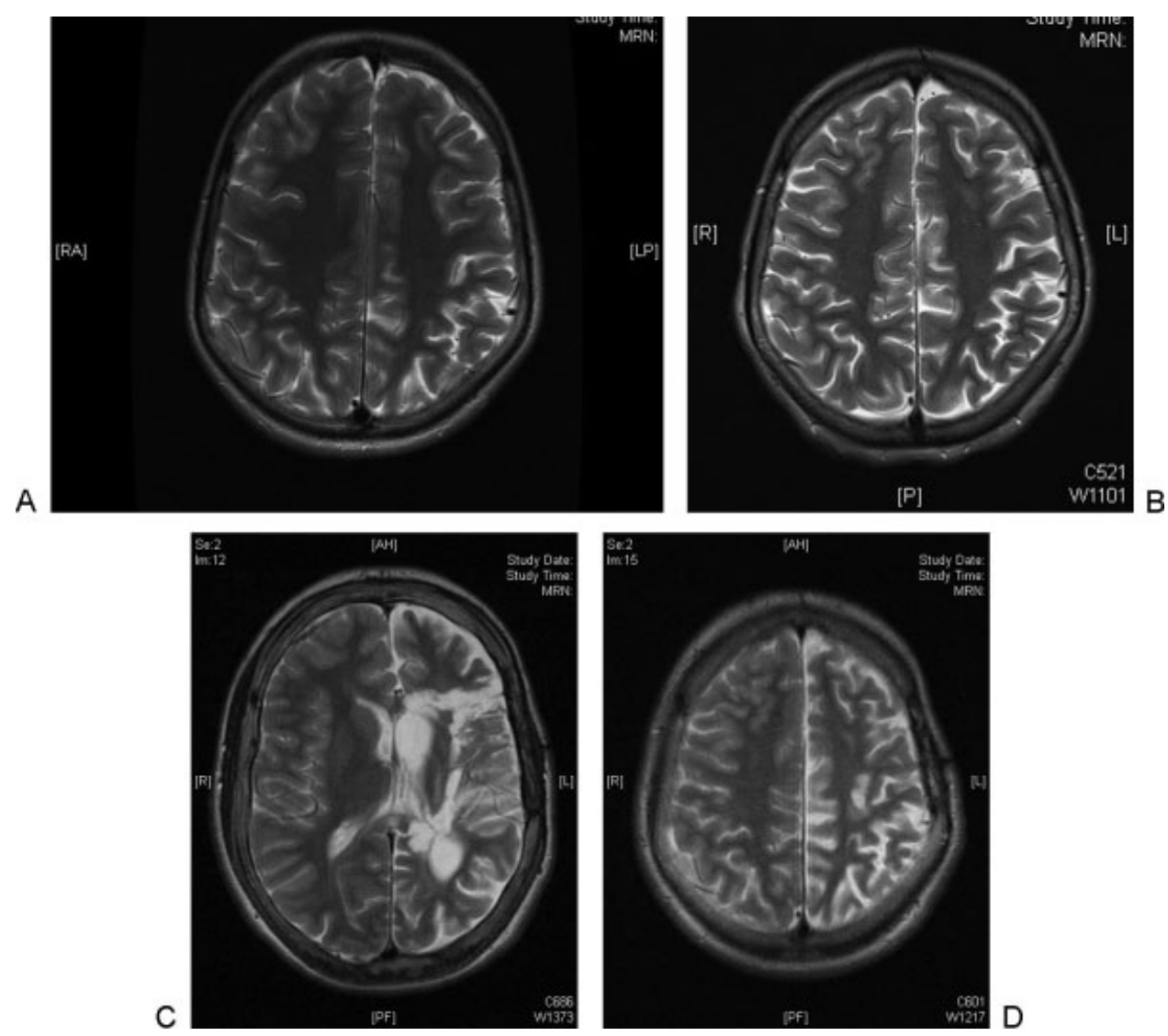

Fig. 1 (A-D) Series of brain axial T2-weighted magnetic resonance images of a boy with left dominant hemisphere Rasmussen syndrome, age of onset at 6 years. He had epilepsy characterized by drug-resistant focal seizures evolving to bilateral convulsive seizures, cognitive decline, and fluctuating right facial and hand weakness. He had a hemispherotomy at age 14 years (- Fig.1 C) and is now seizure-free 20 months later. Images (A) at age 11 years and (B) at age 13 years show progressive left cerebral hemisphere atrophy. (D) Image shows continuing atrophy (direct slice comparison to $\mathbf{F}$ Fig. $\mathbf{1 A}, \mathbf{B})$.

from seizure onset and are a marker of cognitive decline rather than bilateral disease. ${ }^{18}$ No specific EEG abnormalities distinguish RS from other causes of focal epilepsy. Epilepsia partialis continua is not always accompanied by ictal surface EEG change.

\section{Immunohistopathology}

The histopathological hallmarks of RE are unihemispheric cortical inflammation, neuronal loss, and gliosis. Microglial and lymphocytic "nodules," perivascular cuffing, neuronal death, and neuronophagia, are followed by cortical cavitation, marked astrogliosis and neuronal cell loss as end-stage features. Inflammation itself is multifocal within the hemisphere, may involve any area of the brain, and is progressive, consistent with an immunomediated process. ${ }^{19}$

Research for many years focused on antibodies. However, it became clear that relatively few RE patients have GluR3 antibodies. ${ }^{20}$ Since then, other antibodies have been found against $\alpha-7$ nicotinic acetylcholine receptor, and Munc-18-1, which is an intracellular neuronal protein essential for synaptic vesicle release. ${ }^{21,22}$ Recently, VGKC complex antibodies have also been found ${ }^{23}$; nevertheless no one specific autoantibody has been consistently found in RS patients. The role of CNS autoantibodies in the pathogenesis of RE is still unclear.
As focus moved away from antibodies, the pathogenic role of cytotoxic $\mathrm{T}$ lymphocytes has become clearer, with a predominance of $\mathrm{CD}^{+}$cells and around $10 \%$ of these cells positive for granzyme B $\left(\mathrm{GrB}^{+}\right)$, which release cytotoxic granules onto neurons. ${ }^{24}$ These $\mathrm{T}$ cells may be specific to as yet undetermined brain antigens. The identity of such an antigen, auto- or foreign-, remains elusive. Microglial and astroglial activation mirror T-cell infiltration. Astrocytes have been thought to play a role in the pathology of a large variety of epileptic as well as inflammatory disorders of the brain ${ }^{25,26}$ Genes related to activation of helper/inducer and memory/ effector T cells are expressed at higher levels in RS than in patients with cortical dysplasia. ${ }^{27}$

\section{NMDA Receptor Encephalitis}

This severe, but potentially treatable encephalitis is characterized by the presence of antibodies to the N-methyl-Daspartate receptor (NMDAR). The NMDAR is a ligand-gated receptor, permeable to both sodium and calcium, with a voltage-dependent $\mathrm{Mg}^{2+}$ block, activated by glutamate and coligand glycine. Autoantibodies were first reported in young women 15 to 45 years of age presenting with a severe encephalopathy in association with ovarian teratoma. ${ }^{28}$ In adults, a paraneoplastic cause should be sought. The spectrum has since expanded to include both children and adults, 
with emerging differences in presentation by age ${ }^{29} 23 \%$ to $40 \%$ of cases are children. Neuropsychiatric features may be more florid in adults, whereas movement disorder and seizures may be more commonly seen in children, ${ }^{30}$ with behavioral features still prominent. ${ }^{31}$

The classic presentation in adults is of sequential stages: (1) In a few, a prodromal phase, perhaps associated with infection; (2) an early stage with psychosis, confusion, amnesia, and dysphasia; and (3) within 1 to 2 weeks, movement disorders typically choreoathetoid, autonomic instability, hypoventilation, mutism, and catatonia and often reduced consciousness, requiring intensive care treatment. Epilepsy is not usually a predominant feature. ${ }^{32}$

In children, a prodrome is more frequently volunteered with fever and/or associated intercurrent infection. This is followed by seizures in the majority, generalized or focal. The majority also show behavioral changes and confusion. Neuropsychiatric symptoms (agitation, hallucinations) and movement disorder (choreoathetosis, myoclonus, startle, tremor) are observed. About half of these patients need intensive care admission for seizure control or obtundation.

In children and in adults, a brain MRI may not be helpful and in many may be unremarkable. Cortical (mainly limbic and mesial temporal), brainstem, basal ganglia, and cerebellum changes have been reported. Rarely, T2-weighted and fluid-attenuated inversion recovery (FLAIR) hyperintensities or contrast enhancement (in cortical meninges or basal ganglia) are detected. Reversible changes and atrophy have been observed in pediatric series (-Fig. 2). In adults, the EEG may be unremarkable initially, later it may show widespread changes with generalized high-amplitude slow activity. In children, the EEG at presentation, is more likely to be slow consistent with an encephalopathy and early epileptiform discharges may be seen. ${ }^{33}$ One case is reported of antiNMDAR encephalitis mimicking the acute phase of RS. ${ }^{34}$

In CSF, lymphocytic pleocytosis is frequent at onset, as are oligoclonal bands. There is debate as to whether diagnosis is better made from CSF or plasma. ${ }^{35}$ Certainly, concentrations of NMDAR antibodies in serum are high, but there is also high intrathecal synthesis.

If a tumor is present, this should be resected. Early treatment has been associated with better outcome. Firstline immunotherapy is usually steroids (intravenous and/or oral steroids, intravenous immunoglobulin, and/or plasma exchange (PLEX). Second-line immunotherapies, when needed, include cyclophosphamide or monoclonal antibodies (rituximab). ${ }^{5}$

Overall, the outcome is felt to be good, better in paraneoplastic associated disease, but recovery may be slow and relapse not infrequent in both children and adults (up to $25 \%$ ). $^{36}$ Learning, memory, and behavioral sequelae may be elucidated with awareness of this disease. The frequency of relapse raises the issue of the need to consider the risks and benefits of longerterm immunosuppression in selected patients.

\section{Limbic Encephalitis}

First recognized as a paraneoplastic syndrome with amnesia, psychological disturbance, and seizures, knowledge of

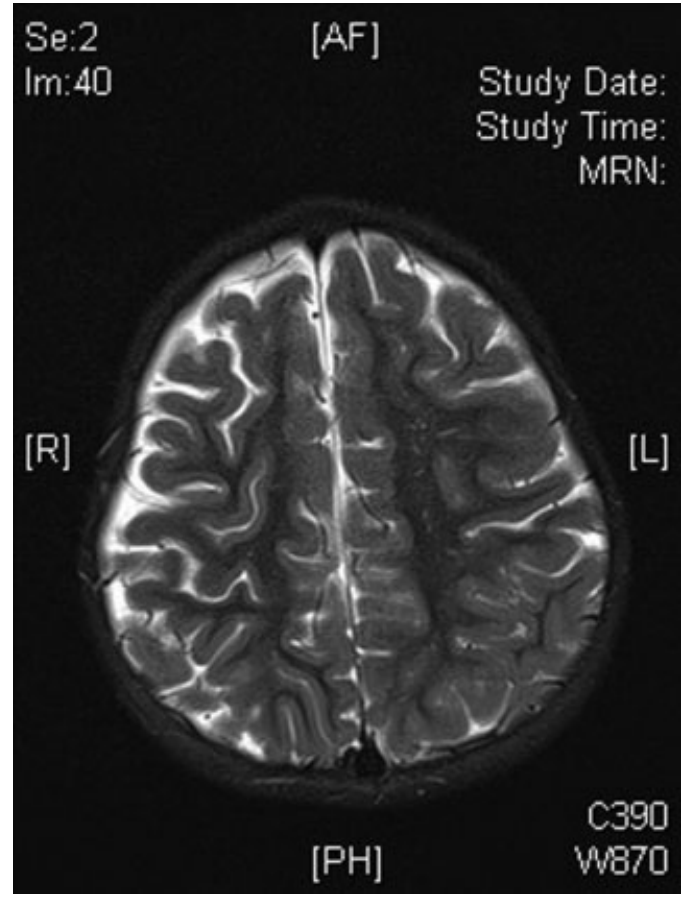

Fig. 2 Brain axial T2-weighted magnetic resonance image showing right cerebral hemisphere atrophy, predominantly frontal in a 2-yearold girl with N-methyl-D-aspartate receptor (NMDAR) encephalitis. The radiological features are similar to Rasmussen syndrome, but are nonprogressive and the clinical picture is different. The child presented at 19 months with poor feeding and vomiting, followed by seizures and a choreiform movement disorder. Recovery has been slow with developmental delay and oropharyngeal dyskinesia. Treatment has included intravenous immunoglobulin, methylprednisolone, and rituximab. NMDAR antibodies have persisted. This child was included in Hacohen et al study. ${ }^{33}$

etiology means that the cause now is more likely to be identified as nonparaneoplastic and antibody-mediated. The main players are antibodies to components of the VGKC-complex, specifically contactin-associated-protein 2 (CASPR2), contactin-2 and leucin-rich, glioma-inactivated 1 (LGI1). ${ }^{37}$ Less frequently seen are antibodies to the NMDAR, AMPAR, GABAR, and GAD. The clinical semiology somewhat corresponds to the antibody detected.

Limbic encephalitis is a disease mainly of men (2:1 ratio), aged 40 years and above. The onset is usually acute or subacute with memory loss, confusion, agitation, and psychiatric symptoms emerging over weeks such that the initial diagnosis is often felt to be an organic psychiatric syndrome. Seizures have mesial temporal semiology and are drug resistant. Sleep disturbance, hypothermia, intestinal pseudo-obstruction, ataxia, and startle syndrome have been reported. The presence of hyponatremia may be a specific clinical clue. Antibody titers are high $(>400 \mathrm{pmol} / \mathrm{L}$ and often $>1000 \mathrm{pmol} / \mathrm{L}) .{ }^{4}$

The EEG shows interictal and ictal temporal, and sometimes frontal, epileptiform activity or slowing. Magnetic resonance imaging may not be helpful; it is normal in almost half of patients. Where it is abnormal, there is usually high signal on T2-weighted or FLAIR, unilaterally or bilaterally, in the mesial temporal lobes or amygdalae. Changes in the temporal lobes may be seen on fluorodeoxyglucose positron 
emission tomography, with early hypermetabolism and late hypometabolism.

Similar to NMDAR antibody encephalitis, a good response to first-line immunotherapy is expected, symptomatically, biochemically, and serologically, with a fall in antibody titers. The disease is monophasic in most, but in a small number of patients, antibodies persist and the course may be chronic or relapsing/remitting. Again, similar to NMDAR antibody encephalitis, patients may be left with functional deficits. More recently, VGKC-complex antibodies are reported in children with limbic encephalitis, status epilepticus, prolonged seizures, and a less-specific encephalopathy syndrome with seizures and psychiatric features. ${ }^{33,38}$ In children, the outcome is less favorable than in adults, with poor response to immunotherapy. ${ }^{38}$

\section{LGI1 Antibody-Associated}

LGI1 is a glycoprotein that associates with synaptic Kv1 VGKCs and is highly expressed in the hippocampus and neocortex. Mutations in LGI1 are known to cause autosomal dominant lateral temporal lobe epilepsy. ${ }^{39}$ As well as limbic encephalitis, antibodies to LGI1 have been found in patients with epilepsy, Morvan syndrome, and faciobrachial dystonic seizures (FBDS). Although FBDS may herald later progression to limbic encephalitis, it is not yet clear if immunotherapy of FBDS will prevent subsequent phenotypic spread. ${ }^{3}$

\section{CASPR2 and Contactin-2 Antibody Associated}

CASPR2 and contactin- 2 are cell-adhesion molecules essential for the localization of VGKCs at neural juxtaparanodes. Mutations affecting CASPR2 are described in a family with cognitive impairment, seizures, and absent deep tendon reflexes. ${ }^{40}$ Antibodies to CASPR2 have been found in limbic encephalitis, neuromyotonia, and in Morvan syndrome (where antibodies against CASPR2 are more frequent than against LGI1). ${ }^{37}$

Morvan syndrome is a rare also potentially treatable autoimmune disease. The onset is more insidious than in limbic encephalitis; the symptoms may be similar-sleep disturbance, psychiatric features, memory loss, and confusion. Clinical clues are caused by neuroendocrine and autonomic dysregulation: cramps, sweating, fasciculations, pain, cardiac arrhythmias, impotence, constipation, and urinary problems. Seizures do not seem to be a feature. Magnetic resonance imaging may be normal. Positive CSF oligoclonal bands may be present. As with the other antibody associated encephalitides, response to immune therapy is reported. An underlying tumor should be sought, especially thymoma.

\section{GABA-Receptor Antibody Encephalitis}

GABA is the main inhibitory neurotransmitter in the brain. There are two GABA receptors, $G A B A_{A}$, the more predominant ligand-gated ion channel, and $\mathrm{GABA}_{\mathrm{B}}$, linked to $\mathrm{G}$-proteins. $\mathrm{GABA}_{B} \mathrm{R}$ antibodies are reported associated with limbic encephalitis, and with an underlying malignancy in half of these patients. $^{8,41} \mathrm{GABA}_{\mathrm{A}} \mathrm{R}$ antibodies have been reported in the presence of high serum and CSF titers in patients with seizures and refractory status epilepticus, and with lower serum-only titers, in patients with neurologic syndromes including stiff-person and adult-onset opsoclonus-myoclonus syndrome. ${ }^{9}$ The spectrum has recently been expanded to include memory impairment with confusion or disorientation, and psychiatric features with hallucinations and anxiety. ${ }^{10}$

\section{Anti-GAD Limbic Encephalitis}

Glutamic acid decarboxylase irreversibly catalyses GABA synthesis from L-glutamic acid. Antibodies to GAD are usually associated with insulin-dependent diabetes and with the spectrum of subacute onset stiff-person disorders, but have also been reported, often at high levels, in up to $10 \%$ of adults with long-standing epilepsy and in limbic encephalitis. ${ }^{12,42}$ Magnetic resonance imaging is more likely to show mesial temporal changes in keeping with inflammation and later scarring. Response to immunotherapy is poor. Like FBDS, there may be a phenotypic spread of the clinical syndrome as noted in the case described in - Fig. 3, which also illustrates the co-existence of antibodies directed against intracellular and neuronal or glial cell-surface expressed antigens.

\section{Antibodies Implicated in the Epilepsies}

Voltage-gated potassium channel, GAD, NMDAR, and glycine receptor antibodies have all been detected in adults with both

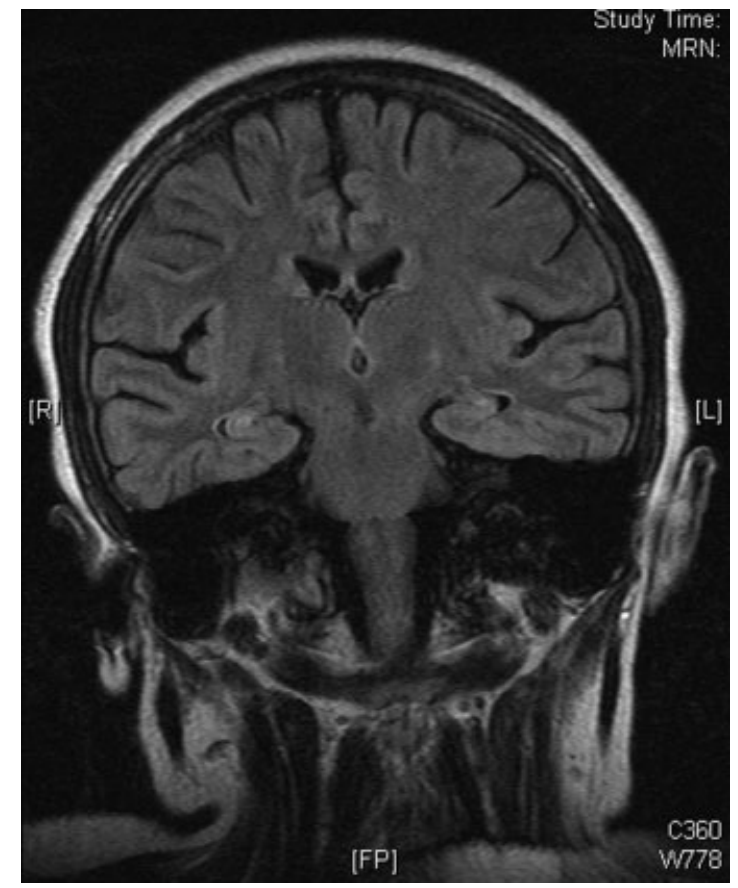

Fig. 3 Brain coronal fluid-attenuated inversion-recovery magnetic resonance image showing bilateral hippocampal sclerosis in a 14-year-old girl with voltage-gated potassium channel (VGKC) and glutamic acid decarboxylase (GAD) antibody-mediated disease. She presented at almost 13 years of age with focal dyscognitive seizures and visual and auditory hallucinations. Seizures continue and are drug resistant. Stiffness and pain, and insulin-dependent diabetes emerged in the year following presentation. She has significant memory and verbal cognitive ability impairment. Treatment has included intravenous immunoglobulin, steroids, plasma exchange, rituximab, mycophenolate, and alemtuzumab. Anti-GAD and anti-VGKC antibodies have been strongly and persistently positive, $>5000 \mathrm{U} / \mathrm{mL}$ and 1440 pM (picomolar). 
established and newly diagnosed epilepsy, at higher prevalence than controls (11\%). ${ }^{43}$ The NMDAR and VGKC-complex antibodies can occasionally be present in patients with neurodegenerative disease, suggesting they are likely to be secondary to the pathology rather than causative. On a more cautious note, antineuronal antibodies are also prevalent in normal healthy controls as well as neuropsychiatric patients and so may not always be pathogenic, ${ }^{44}$ though it is hypothesized that under conditions of BBB dysfunction, antibodies can have pathogenic effects. ${ }^{45}$

\section{Autoantibodies in Cerebral Folate Deficiency}

Cerebral folate deficiency (CFD) is defined as any neurologic syndrome associated with low CSF fluid 5-methyltetrahydrofolate (5MTHF) in the presence of normal peripheral folate metabolism. ${ }^{46}$ Cerebral folate deficiency as a clue to the underlying diagnosis is underrecognized. There are many causes, in which seizures are a significant symptom. Primary CFD may be due to mutations in the gene encoding the folate receptor FR1 expressed in the CNS (FOLR1). Secondary causes include mitochondrial cytopathies and Aicardi-Goutieres syndrome. Autoantibodies against FR1 have been demonstrated in children with infantile-onset irritability, developmental delay, autism, movement disorder, acquired macrocephaly, and epilepsy characterized by myoclonic-astatic, absences, and generalized tonic-clonic seizures. ${ }^{47}$ Treatment of CFD in general is with calcium folinate supplementation, but it is not clear yet in the various different causes whether this will be beneficial. In autoantibody CFD, a partial response to supplementation was reported, better in those treated at a younger age. It has been suggested that cross sensitivity with antigens in cow's milk leads to autoantibody formation. Intriguingly, autoantibody titers reduce on milk-free diets. ${ }^{48}$

\section{Febrile Infection-Related Epilepsy Syndrome (FIRES)}

The acute presentation of recurrent refractory seizures or status epilepticus following a febrile illness in a previously normal individual has been described in adults and children under a variety of names including encephalitis with refractory repetitive partial seizures (AERRPS), severe refractory status epilepticus due to presumed encephalitis, idiopathic catastrophic epileptic encephalopathy, new-onset refractory status epilepticus (NORSE), acute devastating epileptic encephalopathy in school-aged children (DESC), and febrile infection-related epilepsy syndrome (FIRES). The latter has become the adopted term among European authors. The proximity in almost all cases to a preceding febrile illness has raised the possibility that this remains an autoimmune disorder triggered by the infection. In contrast to febrile status epilepticus, the fever preceding the onset of encephalopathy is often low grade or absent. This argues against a fever-induced inflammatory process, but inflammation during the preceding infection may elicit a secondary immune response or may allow existing autoantibodies to access the
CNS. Although known antibodies have been detected in a few with this condition (e.g., anti-GAD 4/12, ${ }^{49}$ neuropil, ${ }^{50}$ and VGKC in isolated reports ${ }^{51}$ ), the numbers relative to cases reported have been small. Further, an underlying predisposition as the result of genetic mutations appears unlikely. ${ }^{52-54}$

Typically, children present following a nonspecific, febrile (in the majority) illness with escalating seizures, more often status epilepticus requiring barbiturate coma in the intensive care unit. Most patients experience focal seizures, reflected in the EEG. Extensive evaluation of CSF for infectious agents and evidence of inflammation has in general proved negative. Magnetic resonance imaging is reported as normal in a little over half; others predominantly show signal abnormalities in the hippocampi or peri-insular region. ${ }^{49}$ Brain biopsies (or analysis of brain from postmortem) have been reported in isolated cases, but have not demonstrated features of inflammation. Response to treatment has been disappointingly poor; steroids and immunoglobulin are those most consistently used, but with variable effect. The only evidence of sustained effect has been reported by Specchio and colleagues who reported a positive response in 2 out of 10 children treated with immunoglobulin; neither of whom required barbiturate coma. ${ }^{55} \mathrm{~A}$ ketogenic diet has also been reported to be effective in some series where antiepileptic drugs have failed. ${ }^{48,56}$ Outcome is consistently poor with around $11 \%$ mortality. ${ }^{49}$ After a period of weeks or months, seizures finally cease or stop, although ultimately $93 \%$ of survivors are reported as having refractory epilepsy, continuing after the acute phase with very few demonstrating preserved cognition. Magnetic resonance imaging in the chronic phase (after at least 6 months) might reveal bilateral mesial temporal atrophy and a T2 hyper signal, but remains negative in half of patients.

The lack autoantibodies and the disappointing response to immunomodulatory treatments raise the question as to the degree this may be an immune condition. Recent discussion has centered around the likelihood that inflammation plays an important role in the pathogenesis, but how treatment may limit the cascade or the inevitable process remains unclear. $^{57}$

\section{Treatment}

Despite emerging evidence on inflammatory and autoimmune bases the mainstays of treatment remain little different from other encephalitides and epilepsy. On presentation with escalating seizures or overt established status epilepticus, acute supportive management is required, with treatment with appropriate antiepileptic drugs as per protocol. Often individuals will prove resistant to standard antiepileptics, with required continuation to barbiturate coma. There is no evidence that etiology at this stage requires a different approach, except a discussion as to the role of immunomodulatory agents in parallel to supportive treatment. This may differ in type and duration according to the presentation.

Acute presentation with repetitive seizures or overt status epilepticus often calls for more aggressive immediate treatment. Bolus methylprednisolone can be administered quickly 
and effectively, with rapid determination of effect. In more subacute presentations oral steroids can be used. Immunoglobulin is usually reserved for treatment where definitive positive autoantibodies are found, although in an acute ITU situation a trial of treatment may be given where suspicion is high. The role of further immunosuppressive agents or plasma exchange in acute presentations will need individual consideration in the presence of positive autoantibodies, but where negative their role remains unclear, with little in the way of positive response reported.

Ketogenic diet has been reported to have a role in acute presentation with status epilepticus, but whether its role is an effect on inflammation over and above any antiepileptic effect remains unknown.

The treatment of Rasmussen syndrome has demanded a different approach, and with the progressive nature presumed to be autoimmune in nature, various groups have attempted immunosuppressive therapy. The natural history has been one of a progressive destruction of one cerebral hemisphere, with treatment with antiepileptic drugs to treat epilepsy, and inevitable surgery in the form of hemidisconnection in time. The assessment has always been timing of surgery, with the concern about the inevitable functional consequence of hemiparesis, hemianopia, and in the case of a language-dominant hemisphere the possibility of dysphasia. Immunosuppressive treatments have been trialed (tacrolimus, ${ }^{13}$ azathiaprine ${ }^{14}$ ). The progress of the disease appears to be slowed rather than halted, with delay in time to surgery compared with historical controls. Monoclonal antibodies have been reported in isolated cases to be of some success, but again the disease process only appears slowed. ${ }^{58,59}$ Some lessons could be learned from other inflammatory disorders such as multiple sclerosis, but without further detail on underlying pathophysiology, the risk is outweighed by the benefit. There appears to be little role for surgery in the management of other immune epilepsies, recognizing that a single focus is unlikely to be responsible for the seizure onset.

\section{Conclusion}

An increasing number of epilepsies are thought to have an immune or possibly an additional inflammatory basis to the underlying pathophysiology. This is likely to have implications for management, looking beyond supportive treatment with conventional antiepileptic drugs. Although in some, definitive biomarkers in the form of recognized autoantibodies may be found, their temporal relationship to the course of the illness may remain unclear. The degree to which such antibodies is causative or secondary to a neurologic insult remains in some circumstances unclear. There appears to be little relationship between titers and the clinical course of the disease. However, there may be a role for such antibodies to play in other epilepsies beyond those with recognized presentations. As we collect more information from research into these disorders, new ways of thinking will develop with regard to management strategies, which in turn will bring improved outcomes.

\section{Disclosures}

SV has sat on Advisory Panels for Eisai and received honoraria for speaking engagements from Cyberonics, Eisai, and UCB with remuneration paid to her department. JHC holds an endowed Chair through the University College, London. She has sat on Advisory Panels for Eisai and Viropharma for which remuneration has been paid to her department. She currently holds grants for research from NIHR, European Union (FP7), Action Medical Research, the Great Ormond Street Hospital Children's Charity, Dravet. org, and SPARKS. She has received grants for research from GW Pharma and Vitaflo. She works as Clinical Advisor to the National Childrens Epilepsy Surgery Service for which remuneration is made to her department.

\section{Acknowledgments}

We are very grateful to Dr. Roxanna Gunny, Consultant Pediatric Neuro-radiologist, Great Ormond Street Hospital NHS Foundation Trust, London, UK for the MRI images, to Drs. Prab Prabhakar and Lucinda Carr, Consultant Pediatric Neurologists, Great Ormond Street Hospital NHS Foundation Trust, London, UK, for the clinical vignettes for - Figs. 2 and 3, and to Dr, Cheryl Hemingway, Consultant Pediatric Neurologist, Great Ormond Street Hospital NHS Foundation Trust, London, UK, for discussion of the immunomediated encephalitides.

\section{References}

1 Varadkar S, Bien CG, Kruse CA, et al. Rasmussen's encephalitis: clinical features, pathobiology, and treatment advances. Lancet Neurol 2014;13(2):195-205

2 Rogers SW, Andrews PI, Gahring LC, et al. Autoantibodies to glutamate receptor GluR3 in Rasmussen's encephalitis. Science 1994;265(5172):648-651

3 Irani SR, Gelfand JM, Al-Diwani A, Vincent A. Cell-surface central nervous system autoantibodies: clinical relevance and emerging paradigms. Ann Neurol 2014;76(2):168-184

4 Vincent A, Bien CG, Irani SR, Waters P. Autoantibodies associated with diseases of the CNS: new developments and future challenges. Lancet Neurol 2011;10(8):759-772

5 Dalmau J, Lancaster E, Martinez-Hernandez E, Rosenfeld MR, Balice-Gordon R. Clinical experience and laboratory investigations in patients with anti-NMDAR encephalitis. Lancet Neurol 2011; 10(1):63-74

6 Buckley C, Oger J, Clover L, et al. Potassium channel antibodies in two patients with reversible limbic encephalitis. Ann Neurol 2001; 50(1):73-78

7 Lai M, Hughes EG, Peng X, et al. AMPA receptor antibodies in limbic encephalitis alter synaptic receptor location. Ann Neurol 2009; 65(4):424-434

8 Lancaster E, Lai M, Peng X, et al. Antibodies to the GABA(B) receptor in limbic encephalitis with seizures: case series and characterisation of the antigen. Lancet Neurol 2010;9(1): 67-76

9 Petit-Pedrol M, Armangue T, Peng X, et al. Encephalitis with refractory seizures, status epilepticus, and antibodies to the GABAA receptor: a case series, characterisation of the antigen, and analysis of the effects of antibodies. Lancet Neurol 2014;13(3): 276-286 
10 Pettingill P, Kramer HB, Coebergh JA, et al. Antibodies to GABAA receptor $\alpha 1$ and $\gamma 2$ subunits: Clinical and serologic characterization. Neurology 2015;84(12):1233-1241

11 Malter MP, Helmstaedter C, Urbach H, Vincent A, Bien CG. Antibodies to glutamic acid decarboxylase define a form of limbic encephalitis. Ann Neurol 2010;67(4):470-478

12 Bien CG, Granata T, Antozzi C, et al. Pathogenesis, diagnosis and treatment of Rasmussen encephalitis: a European consensus statement. Brain 2005;128(Pt 3):454-471

13 Bien CG, Tiemeier H, Sassen R, et al. Rasmussen encephalitis: incidence and course under randomized therapy with tacrolimus or intravenous immunoglobulins. Epilepsia 2013;54(3):543-550

14 Lamb K, Scott WJ, Mensah A, Robinson R, Varadkar S, Cross JH. Prevalence and clinical outcome of Rasmussen encephalitis in children from the United Kingdom. Dev Med Child Neurol 2013;55 (Suppl 1):14

15 Oguni H, Andermann F, Rasmussen TB. The natural history of the syndrome of chronic encephalitis and epilepsy: a study of the MNI series of forty-eight cases. In: Andermann F, ed. Chronic Encephalitis and Epilepsy-Rasmussen's Syndrome. Boston, MA: Butterworth-Heinemann; 1991:7-35

16 Frucht S. Dystonia, athetosis, and epilepsia partialis continua in a patient with late-onset Rasmussen's encephalitis. Mov Disord 2002;17(3):609-612

17 Bien CGM, Urbach H, Deckert M, et al. Diagnosis and staging of Rasmussen's encephalitis by serial MRI and histopathology. Neurology 2002;58(2):250-257

18 Longaretti F, Dunkley C, Varadkar S, Vargha-Khadem F, Boyd SG, Cross JH. Evolution of the EEG in children with Rasmussen's syndrome. Epilepsia 2012;53(9):1539-1545

19 Pardo CA, Vining EPG, Guo L, Skolasky RL, Carson BS, Freeman JM. The pathology of Rasmussen syndrome: stages of cortical involvement and neuropathological studies in 45 hemispherectomies. Epilepsia 2004;45(5):516-526

20 Watson R, Jepson JE, Bermudez I, et al. Alpha7-acetylcholine receptor antibodies in two patients with Rasmussen encephalitis. Neurology 2005;65(11):1802-1804

21 Watson R, Jiang Y, Bermudez I, et al. Absence of antibodies to glutamate receptor type 3 (GluR3) in Rasmussen encephalitis. Neurology 2004;63(1):43-50

22 Yang R, Puranam RS, Butler LS, et al. Autoimmunity to munc-18 in Rasmussen's encephalitis. Neuron 2000;28(2):375-383

23 Spitz MA, Dubois-Teklali F, Vercueil L, et al. Voltage-gated potassium channels autoantibodies in a child with rasmussen encephalitis. Neuropediatrics 2014;45(5):336-340

24 Bien CG, Bauer J, Deckwerth TL, et al. Destruction of neurons by cytotoxic T cells: a new pathogenic mechanism in Rasmussen's encephalitis. Ann Neurol 2002;51(3):311-318

25 Aronica E, Ravizza T, Zurolo E, Vezzani A. Astrocyte immune responses in epilepsy. Glia 2012;60(8):1258-1268

26 Bauer J, Elger CE, Hans VH, et al. Astrocytes are a specific immunological target in Rasmussen's encephalitis. Ann Neurol 2007;62(1):67-80

27 Owens GC, Huynh MN, Chang JW, et al. Differential expression of interferon- $\gamma$ and chemokine genes distinguishes Rasmussen encephalitis from cortical dysplasia and provides evidence for an early Th1 immune response. J Neuroinflammation 2013;10:56

28 Dalmau J, Tüzün E, Wu HY, et al. Paraneoplastic anti-N-methyl-Daspartate receptor encephalitis associated with ovarian teratoma. Ann Neurol 2007;61(1):25-36

29 Florance NR, Davis RL, Lam C, et al. Anti-N-methyl-D-aspartate receptor (NMDAR) encephalitis in children and adolescents. Ann Neurol 2009;66(1):11-18

30 Armangue T, Titulaer MJ, Málaga I, et al; Spanish Anti-N-methylD-Aspartate Receptor (NMDAR) Encephalitis Work Group. Pediatric anti-N-methyl-D-aspartate receptor encephalitis-clinical analysis and novel findings in a series of 20 patients. J Pediatr 2013; 162(4):850-856.e2
31 Wright S, Hacohen Y, Jacobson L, et al. N-methyl-D-aspartate receptor antibody-mediated neurological disease: results of a UK-based surveillance study in children. Arch Dis Child 2015

32 Dalmau J, Gleichman AJ, Hughes EG, et al. Anti-NMDA-receptor encephalitis: case series and analysis of the effects of antibodies. Lancet Neurol 2008;7(12):1091-1098

33 Hacohen $Y$, Wright $S$, Waters $P$, et al. Paediatric autoimmune encephalopathies: clinical features, laboratory investigations and outcomes in patients with or without antibodies to known central nervous system autoantigens. J Neurol Neurosurg Psychiatry 2013;84(7):748-755

34 Greiner H, Leach JL, Lee KH, Krueger DA. Anti-NMDA receptor encephalitis presenting with imaging findings and clinical features mimicking Rasmussen syndrome. Seizure 2011;20(3):266-270

35 Gresa-Arribas N, Titulaer MJ, Torrents A, et al. Antibody titres at diagnosis and during follow-up of anti-NMDA receptor encephalitis: a retrospective study. Lancet Neurol 2014;13(2): 167-177

36 Titulaer MJ, McCracken L, Gabilondo I, et al. Treatment and prognostic factors for long-term outcome in patients with antiNMDA receptor encephalitis: an observational cohort study. Lancet Neurol 2013;12(2):157-165

37 Irani SR, Alexander S, Waters P, et al. Antibodies to Kv1 potassium channel-complex proteins leucine-rich, glioma inactivated 1 protein and contactin-associated protein- 2 in limbic encephalitis, Morvan's syndrome and acquired neuromyotonia. Brain 2010; 133(9):2734-2748

38 Haberlandt E, Bast T, Ebner A, et al. Limbic encephalitis in children and adolescents. Arch Dis Child 2011;96(2):186-191

39 Morante-Redolat JM, Gorostidi-Pagola A, Piquer-Sirerol S, et al. Mutations in the LGI1/Epitempin gene on 10q24 cause autosomal dominant lateral temporal epilepsy. Hum Mol Genet 2002;11(9): 1119-1128

40 Strauss KA, Puffenberger EG, Huentelman MJ, et al. Recessive symptomatic focal epilepsy and mutant contactin-associated protein-like 2. N Engl J Med 2006;354(13):1370-1377

41 Höftberger R, Titulaer MJ, Sabater L, et al. Encephalitis and GABAB receptor antibodies: novel findings in a new case series of 20 patients. Neurology 2013;81(17):1500-1506

42 Kwan P, Sills GJ, Kelly K, Butler E, Brodie MJ. Glutamic acid decarboxylase autoantibodies in controlled and uncontrolled epilepsy: a pilot study. Epilepsy Res 2000;42(2-3):191-195

43 Brenner T, Sills GJ, Hart Y, et al. Prevalence of neurologic autoantibodies in cohorts of patients with new and established epilepsy. Epilepsia 2013;54(6):1028-1035

44 Dahm L, Ott C, Steiner J, et al. Seroprevalence of autoantibodies against brain antigens in health and disease. Ann Neurol 2014; 76(1):82-94

45 Levin EC, Acharya NK, Han M, et al. Brain-reactive autoantibodies are nearly ubiquitous in human sera and may be linked to pathology in the context of blood-brain barrier breakdown. Brain Res 2010;1345(0):221-232

46 Hyland K, Shoffner J, Heales SJ. Cerebral folate deficiency. J Inherit Metab Dis 2010;33(5):563-570

47 Ramaekers VT, Rothenberg SP, Sequeira JM, et al. Autoantibodies to folate receptors in the cerebral folate deficiency syndrome. $\mathrm{N}$ Engl J Med 2005;352(19):1985-1991

48 Ramaekers VT, Sequeira JM, Blau N, Quadros EV. A milk-free diet downregulates folate receptor autoimmunity in cerebral folate deficiency syndrome. Dev Med Child Neurol 2008;50(5): 346-352

49 Kramer U, Chi CS, Lin KL, et al. Febrile infection-related epilepsy syndrome (FIRES): pathogenesis, treatment, and outcome: a multicenter study on 77 children. Epilepsia 2011;52(11):1956-1965

50 Milh M, Villeneuve N, Chapon F, et al. New onset refractory convulsive status epilepticus associated with serum neuropil auto-antibodies in a school aged child. Brain Dev 2011;33(8): 687-691 
51 Illingworth MA, Hanrahan D, Anderson CE, et al. Elevated VGKCcomplex antibodies in a boy with fever-induced refractory epileptic encephalopathy in school-age children (FIRES). Dev Med Child Neurol 2011;53(11):1053-1057

52 van Baalen A, Hausler M, Plecko-Startinig B, et al. Febrile Infection Related Epilepsy Syndrome without detectable antibodies and response to immunotherapy: a case series and discussion of epileptogenesis in FIRES. Neuropediatrics 2012; 43:209-216

53 Carranza Rojo D, Harvey AS, Iona X, et al. Febrile infection-related epilepsy syndrome is not caused by SCN1A mutations. Epilepsy Res 2012;100(1-2):194-198

54 Appenzeller S, Helbig I, Stephani U, et al. Febrile infection-related epilepsy syndrome (FIRES) is not caused by SCN1A, POLG, PCDH19 mutations or rare copy number variations. Dev Med Child Neurol 2012;54(12):1144-1148
55 Specchio N, Fusco L, Claps D, Vigevano F. Epileptic encephalopathy in children possibly related to immune-mediated pathogenesis. Brain Dev 2010;32(1):51-56

56 Nabbout R, Mazzuca M, Hubert P, et al. Efficacy of ketogenic diet in severe refractory status epilepticus initiating fever induced refractory epileptic encephalopathy in school age children (FIRES). Epilepsia 2010;51(10):2033-2037

57 Nabbout R, Vezzani A, Dulac O, Chiron C. Acute encephalopathy with inflammation-mediated status epilepticus. Lancet Neurol 2011;10(1):99-108

58 Bittner S, Simon OJ, Göbel K, Bien CG, Meuth SG, Wiendl H. Rasmussen encephalitis treated with natalizumab. Neurology 2013;81(4):395-397

59 Thilo B, Stingele R, Knudsen K, et al. A case of Rasmussen encephalitis treated with rituximab. Nat Rev Neurol 2009;5(8): 458-462 